\title{
O falo e a sociedade do consumo
}

\section{The phallus and the consumer society}

\author{
Diego Saimon de Souza Abrantes ${ }^{1 *}$, Alex Wagner Leal Magalhães 2 \\ ${ }^{1}$ Psicólogo/coach, Professor Mestre no Instituto Macapaense do Melhor Ensino Superior. Macapá-AP Brasil. E-mail: \\ diego_saimon@hotmail.com *Autor para correspondência \\ ${ }^{2}$ Psicólogo, Professor Mestre e coordenador de Psicologia do Centro Universitário Metropolitano da Amazônia, doutorando do programa de \\ pós-graduação em Psicologia da Universidade Federal do Pará. Brasil. E-mail: alexwmagalhaes@yahoo.com.br
}

\author{
Palavras-chave \\ Falo \\ Complexo de édipo \\ Consumo \\ Sociedade do consumo
}

Intrigam ações cada vez mais consumistas da população geral e um olhar psicanalítico minucioso cobre-se de curiosidade a respeito de como a Psicanálise interpretaria esse movimento social constante. Idealizando-se que o falo tem deveras participação nisso, correlacionar falo e sociedade do consumo foi a busca empreendida neste estudo. Através da interpretação psicanalítica de 55 obras, desde artigos científicos publicados no intervalo de 10 anos, que compreende o início do século à 2011, a obras clássicas da Psicanálise, Filosofia e Sociologia. Disserta-se, psicanaliticamente, sobre como o lugar de falta, em nossa condição de supostos detentores do falo, gera uma angústia que precisa ser vencida, levando-nos a atender, inconscientemente, a demanda do consumo do mercado, em que tamponamos esse lugar de faltosos com mercadorias e/ou serviços engajadas no circuito do consumo próprio do capitalismo, metamorfoseando-se em nosso circuito do desejo.

Keywords
Phallus
Oedipus complex
Consumption
Consumer society

\begin{abstract}
It intrigues the increasingly consumerist behavior of the general population and a thorough psychoanalytic look is filled with curiosity as to how psychoanalysis would interpret this constant social movement. Idealizing that the phallus has indeed participation in this, correlating phallus and consumer society was the pursuit undertaken in this study. Through the psychoanalytic interpretation of 55 works, from scientific articles published in the interval of 10 years that goes from the beginning of the century to 2011 to classic works of Psychoanalysis, Philosophy and Sociology, it is discussed as the place of lack, in our condition of supposed holders of the phallus generates an anguish that needs to be overcome, leading us unconsciously to meet the demand of market consumption, in which we buffer this place of the defaulters with goods and/or services engaged in the circuit of capitalism's own consumption, metamorphosing in our desire circuit.
\end{abstract}

\section{INTRODUÇÃO}

Este estudo propõe-se a analisar um dos elementos, dentro da Psicanálise, tão discutido e abordado, mas que ainda, com tantos anos, permanece funcionando como uma grande incógnita de muitos temas da ciência iniciada por Freud. Eis tal elemento: o falo. Bem, este é apenas o primeiro, pois o segundo elemento mostra-se como atenuante de um movimento tão antigo e atual: mercadoria, consumo, cultura do consumo, sociedade de consumo. São variados termos designando um único centro da proposta, o consumir.

Ao apresentar o termo "falo", começa-se a se repensar nas referências psicanalíticas que formam a esfera ao qual se centra esta pesquisa. Portanto, pensa-se em falo enquanto, impreterivelmente, a terminologia de caráter simbólico na vida de um sujeito e não em seu caráter anatômico (LAPLANCHE; PONTALIS, 2008). Se falar em anatomia, falo nada mais é do que o pênis, ou como diria Koogan e Houaiss (1998, p. 659): "objeto culto entre os antigos, que o veneravam como símbolo de natureza criadora/pênis". De modo característico, falo representaria, a grosso modo, poder, o poder pertencente àquele detentor do falo, pensando psicanaliticamente, todavia não se trata de uma expressão machista, apenas simbólica. Essa característica de representatividade de algo que é dada ao falo, resgata o conceito de significante de Lacan (1998). Isto é, implica dizer que ele tem algum significado, é um elemento que simboliza algo, que significa alguma coisa para uma pessoa, grupo social, sociedade, enfim, um significante.

O segundo elemento essencial analisado é a mercadoria, o consumo de mercadorias como partícula extremamente intricada na discussão do falo, visto a configuração da sociedade atual, predominantemente capitalista, visando a compra e venda como fatores de alimentação e retroalimentação de um mercado social que necessita disso para sobreviver e não ser excluído mundialmente. Barbosa (2010) salienta que uma sociedade de consumo é formada no momento em que quase como uma filosofia moral daquele grupo, o consumo de mercadorias e serviços é hábito corriqueiro e necessário para a manutenção do sentimento de 
pertença àquela dada sociedade. É quase como se você fosse coagido a ser consumista. Essa coerção é algo que interessa neste artigo, isto é, o lado psíquico desse desejo de consumir.

Esses produtos consumidos, significantes fálicos de algum modo, alimentam o "mercado do desamparo". Freud (2010b) e Birman (2011) retratam em suas obras $O$ mal-estar na civilização e Mal-estar na atualidade, respectivamente, o quão grande é o nível de desamparo a que os sujeitos estão submetidos, numa progressão geométrica linear. Para evitar qualquer infelicidade, tencionam-se buscas (mais e mais laboriosas) por formas de evitar o desprazer (FREUD, 2010b). Precisa-se salvaguardar que na passagem citada acima, Freud depreende que o desamparo é uma condição natural do ser humano, pois nasce-se assim, precisando de amparo de pais para sobreviver, caso contrário, morre-se, porém quando se discute o aumento do nível de desamparo, está se falando que com as mudanças históricas e de contexto atual, como por exemplo, filhos passando mais tempo nas escolas (escolas de período integral), pai e mãe mais distantes dos filhos por conta de trabalho, bebês se desenvolvendo na maior parte do dia em creches, cobranças sociais pelo corpo esbelto, pela profissão mais rentável, relacionamentos através de redes sociais e etc., isso parece tão mais presente e evidente.

É relevante falar que essas mudanças afetam o narcisismo do sujeito. Freud (2010a), em A introdução ao narcisismo, explica que o narcisismo é essencial a todos seres humanos. Varia-se, assim, a ocorrência de sintomas entre uma e outras pessoas. Esse narcisismo, em poucas palavras, refere-se ao investimento libidinal (de energia psíquica, na psicanálise) em si mesmo. Veja bem, entender que existe um "mercado do desamparo" é entender que todos estão sujeitos ao desejo de evitar a dor, medo, desprazer do sentimento do desamparo. Desse modo, para Freud, na obra já referida, somos constantemente impelidos, pelo narcisismo, a buscarmos o prazer e evitarmos o desprazer. No caso que tratado aqui, o prazer pode estar numa mercadoria.

A intenção desta pesquisa clarifica-se mais agora, ao se entender que se está comprando felicidades em frascos, caixas, sacolas e embrulhos, mercadorias que fortunam um mercado financeiro e social que se aproveita disso. 0 mercado está astuto aos mais cegos limiares, desbravando-os, sem que se perceba, permanecendo e fortalecendo o desejo inconsciente do consumir. Partindo desse princípio, buscou-se correlacionar, com amplo estudo bibliográfico, a postura fálica da sociedade atual com a cultura do consumo na pósmodernidade.

A pesquisa proposta é mais atual do que se pensa, tecendo modos que parecem que farão dela um ponto de partida para tantas outras, pois no mundo pós-moderno, há tanto o que se ver, afinal, quanto mais se avança na ciência social, menos se sabe e mais possibilidades se abrem para o estudo da mente humana. Há quem defina a sociedade atual como sociedade de consumo, autores que serão apresentados no decorrer da leitura, como Barbosa (2010) e Baudrillard (2010), e esta é responsável por fazer desta discussão uma pertinência petulante.

Valida-se as indagações deste estudo frente a uma situação social de crescente desamparo e medo, sobrepujando-se isso com mercadorias substitutivas dos reais desejos humanos. Até este aspecto, é uma incógnita do mundo pós-moderno, a real necessidade de nossos desejos ou o que nossos desejos realmente querem significar.

Este tema é uma constante atual e não pode ser indiferenciada de outros aspectos sociais no mundo. É algo a se pensar desde antigamente, porém, muito mais claro hoje em dia, em uma sociedade neoliberal que apregoa o consumo de forma contínua, como forma de alimentar o mercado e obter lucro. A ciência está mais fortalecida que nunca, as tecnologias mais presentes e dominantes e a subjetividade inconsciente lida com isso de algum jeito.

A escassez de estudos mais detalhados evidencia lacunas nesse viés científico da psicanálise, ou seja, faltam informações mais abrangentes e detalhadamente estudadas sobre o assunto. A relevância deste estudo pauta-se na vívida procura e conclusão da escassez de bibliografias, escritos, artigos, registros de pesquisas desse tipo, que trabalham com as relações supracitadas, tornando os anseios descritos plausíveis e seus resultados novos.

A pesquisa lida até aqui, pode ganhar um caráter crítico e moral (pois não está se indagando o certo e o errado) da sociedade de consumo, no entanto, este não é o objetivo, mas sim um estudo psicanalítico e social a respeito da relação que todas as pessoas desenvolvem com a mercadoria e o que ela, inconscientemente falando, representaria, fazendo parecer, essas mesmas pessoas, reles seres frágeis condenados a desejos de consumo sem ao menos conseguir explanar o porquê deles. Isto se deve, porquê, talvez, a resposta esteja muito além do que os olhos podem ver, as mentes rememorar e os "bolsos" comprar.

\section{METODOLOGIA}

\section{Amostra, tipologia e delineamento do estudo}

Realizou-se uma pesquisa bibliográfica que, conforme Martins e Lintz (2011 p.15), é aquela pesquisa em que se busca a explanação e discussão de um tema ou problema com base em referencial teórico de livros, revistas, periódicos, entre outros. Foram, portanto, utilizados artigos científicos publicados no período entre 2001 a 2011 nas redes de pesquisa Scielo e Bireme, e livros de Psicanálise e afins de 
outras ciências, como Filosofia e Sociologia.

Os artigos científicos deviam possuir as palavras chaves: sociedade de/do consumo, consumo, consumismo, sociedade fálica, falocentrismo, falo, complexo de édipo, nome-do-pai, sociedade do espetáculo, espetáculo social, indústria cultural, narcisismo, mercadoria. Tais palavras-chave foram usadas como temas a serem considerados para os livros analisados.

É preciso justificar, de antemão, a decisão de que os artigos científicos utilizados tivessem sido publicados de 2001 a 2011. Birman (2011) faz em seu trabalho Mal-estar na atualidade uma alusão à discussão antagônica entre o discurso freudiano sobre o sujeito harmonicamente social e um sujeito aludido pelo mal-estar e desamparo, segundo ele, características da modernidade. Este estudo pautou-se na pós-modernidade, pois traz tais características da modernidade, conforme Birman, muito mais desencadeadas e desenvolvidas, onde o sentimento de desamparo é muito maior e degradante socialmente, pensando ainda, nos fortes avanços tecnológicos ocorridos neste período, como o desenvolvimento desenfreado das tecnologias de informação e robótica, capacitando, quase que qualquer coisa, em forma de produtos ou mercadorias que abarcam o desamparo social ou o fortalece.

A curiosidade científica aqui sementada foi baseada na premissa de se usar as publicações datadas do primeiro ano do século XXI até o período completo de uma década, isto é, de 2001 a 2011. Desejava-se estudar toda produção publicada em forma de artigo científico dentro desse intervalo de tempo de modo que os resultados demonstrassem o que se havia de descobertas sobre os objetos de estudo dentro da primeira década do atual século.

Sendo este um estudo psicanalítico, não se pretendeu estipular intervalo de tempo para os livros, somente um limite final que eram livros publicados até 2011. Isso ocorreu pois se desejou usar desde as obras clássicas e históricas da Psicanálise, Filosofia e Sociologia até as mais atuais compreendido o mesmo limite temporal atribuído aos artigos científicos.

Ressalta-se o uso de 55 obras analisadas, psicanaliticamente, no decurso de 10 meses e que o presente artigo é resultado desse estudo apresentado, anteriormente, em forma de monografia.

\section{Procedimentos e análise dos dados}

Após a leitura de cada obra, todas tiveram trechos considerados importantes destacados, acompanhados de anotação à parte em bloco de notas sobre o discurso ali desenvolvido, que conforme Gil (2008), serve para colaborar na organização das informações a serem suplantadas no texto científico, servindo também para a criação de fichas de documentação, o fichamento. Portanto, em outro bloco de notas, foi feito um pequeno fichamento de cada obra pesquisada, organizando-as e separando-as por discussões centrais.

Realizou-se, primeiramente, uma análise interpretativa para conceituação de falo em Psicanálise. Depois fez-se o cerceamento da visão psicanalítica da sociedade de consumo na pós-modernidade. Somente com tudo isso concluído, partiu-se para a análise correlacional entre o conceito de falo e a sociedade de consumo na pós-modernidade, sendo, posteriormente, interpretadas, mais uma vez, pelas vias psicanalíticas.

\section{FALO, UMA CONCEPÇÃO SIMBÓLICA}

É preciso, antes de qualquer coisa, a compreensão do conceito de falo em psicanálise, divergente do conceito médico-biológico ou do que venha nos dicionários de língua portuguesa. A exemplo, temos falo como um substantivo masculino, designador do pênis, representação do pênis como símbolo da fecundidade da natureza (XIMENES, 1999), ou apenas "pênis", conforme o dicionário Aurélio (FERREIRA, 2004, p. 317). Esta proposição é uma grande falácia sob a perspectiva psicanalítica.

Freud (2011) se preocupou em distinguir, em $A$ organização genital infantil, o uso do termo falo, efetuando a mesma distinção realizada mais acima, acentuando o caráter simbólico, representativo do falo e não propriamente do órgão sexual pênis em si. No entanto, o grande explorador do conceito de falo foi Lacan, pois ele percebeu que ali se encontrava o elemento circundante dos processos psíquicos humanos. No tocante a Freud, falo foi um tema muito explorado, embora para Lacan, o pai da Psicanálise possa não ter sido muito objetivo, sendo importante acentuar a prevalência do falo na teoria freudiana (NASIO, 1997). "Lacan esforçou-se em mostrar o quanto esta referência (falo) era constante e central na obra freudiana" (DOR, 2003, p. 71); Kaufmann (1996) complementa esse sentido ao dizer que Lacan estendeu o domínio do falo muito além dos próprios limites sugeridos por ele.

Lacan (1998) explica que falo, em uma doutrina freudiana, é um significante. "O falo não é exatamente o pênis orgânico, ou algum signo de potência, mas um significante puro" (SAFATLE, 2007, p. 55). Ao falar de significante, isso traz a obrigação de ser ter a ideia signatária de significante: significante aponta aquilo que tem uma significação, a que se dá significado, é o elemento que qualitativamente o comporta, que tem algum valor de signo, um ponto determinante no funcionamento do sujeito (ROUDINESCO, 1998), como o termo "amor" ser um significante social na 
cultura brasileira daquilo que é emocionalmente bonito de sentir por outra pessoa, como por exemplo, amar-se a família, amar-se os amigos, amar-se a esposa ou marido.

\section{O complexo de édipo / nome-do-pai}

É notável este período a que todos seres humanos passam. Se você é um menino, notará que algumas pessoas não tem pênis e descobrirá que na verdade existem meninos e meninas. Se você é uma menina, então poderá pensar que Ihe falta alguma coisa na região entre as pernas. Percebe-se que no meio disso tudo, parece haver algo central: o pênis. No entanto, não é por ele que a criança, de alguma forma, angustiar-se-á, porém pelo significante disso tudo, ou seja, o que convém a este estudo, o falo em seu caráter simbólico, simbolizado através da presença ou ausência do pênis orgânico.

Freud chega a trabalhar essa pequena estória em três trabalhos seus, sendo eles $A$ organização genital infantil (1923), A dissolução do complexo de Édipo (1924) e Algumas consequências da diferença anatômica entre os sexos (1925). No segundo texto citado, Freud (2011) alerta de que a criança sucumbe à ameaça da castração, própria do complexo de Édipo, isto no menino, sucumbe, pois à angústia de ser castrado e perder seu pênis, como, em sua fantasia, aconteceu com a menina. Somente no terceiro texto, Freud (2011) começa a extenuar de forma mais detalhada o complexo de Édipo para a menina.

A palavra falo não vem à toa, falo chega a ser indicativo de fálico, fálica, fase fálica, isto é, justamente o período do desenvolvimento psicossexual humano em que o falo entra em cena, de modo que a criança começa a distinguir os sexos (COSTA, 2011). Isso se dá a partir do momento em que ela nota a ausência do pênis em algumas pessoas e sua presença em outras. O que decorrerá daqui se deve ao caráter simbólico do falo e não do órgão reprodutor masculino. Sim, apenas se considera, nesse momento, o órgão fálico, denotando o que Freud (2011, p. 171) denomina de primazia do falo:

A principal característica dessa 'organização genital infantil' constitui, ao mesmo tempo, o que diferencia da definitiva organização genital dos adultos. Consiste no fato de que, para ambos os sexos, apenas um genital, o masculino, entra em consideração. Não há, portanto, uma primazia genital, mas uma primazia do falo.

Durante o complexo de Édipo, o menino, a partir da distinção com a menina, vê-se temeroso, pois acredita que a menina tenha sofrido uma mutilação do órgão fálico devido a alguma atitude ruim, desaprovada, culpada por impulsos ruins, proibidos (FREUD, 2011), como o desejo inconsciente de permanecer ligada à mãe. Logo, ele percebe que a mãe também não detém falo e se pega em outra angústia. Neste momento, ele identifica-se com aquele que supostamente tem o falo, pois conquistou essa mulher que ele tanto deseja, assim, identifica-se com o pai (FREUD, 2011). Este seria o famoso momento da competição do filho com o "homem da casa" pelo amor da "mulher da casa", enquanto após o efeito castrador da função paterna, o menino volta-se à identificação com aquele a quem a mãe atribui seu afeto, como complementa Dor (1997), afirmando que ao perceber que a mãe não deseja apenas a ela, a criança, imaginariamente, vê isso como uma rivalidade contra aquele a quem o desejo da mãe se foca. Veja bem, não se fala propriamente do pai, o pai real, pois está se falando de uma função paterna e que nem sempre está diretamente ligado ao pai biológico.

Para Dor (2003), a referência ao falo, que Lacan faz, é a referência ao pai, a função que media a relação mãe e criança e vice-versa (daqui parte a denominação Nome-do-Pai dada por Lacan ao complexo de Édipo). Nasio (1997) explica que a mãe coloca seu filho como um falo imaginário pertencente a si, e o filho identifica-se com esse lugar a fim de preencher o desejo materno. Isso é referente à dissolução dada ao complexo de Édipo pela menina. Resgatando Freud (2011), entende-se que a menina, de outra forma, procede à resolução de sua fase fálica. Isto vem esculpido no aspecto de a menina não compreender sua falta de pênis por sua condição natural - lembrando que até aqui, nem a menina e nem o menino distinguem os sexos, fantasiando que são todos iguais anatomicamente, obviamente, até começarem a perceber que há algo diferente - assim, a menina passa a acreditar que foi castrada.

Remete-se à questão de que a menina aceita a castração, já o menino, passa a temer isso. Daí, portanto, a menina, angustia-se com sua mãe, essa mulher que não lhe foi justa, que não lhe deu falo, isto também até perceber que sua mãe foi castrada, como ela, isto é, não tem pênis também. É aqui que a menina envolve suas energias para o pai. Freud (2011, p. 212) ainda pontua que "a renúncia ao pênis não é tolerada sem uma tentativa de compensação" e em decorrência disso, a menina passa do pênis ao bebê, isto é, ao desejo duradouro de ser mãe, como se considerasse que isso seria a fonte de gozo fálico, de conquista, assim como sua mãe, daquele homem que detêm o falo, seu pai. Lacan (1998) explica que em todo esse processo, a significação da castração só se torna eficiente ao proceder na formação dos sintomas, a partir de sua descoberta como castração da mãe.

Lacan introduz o elemento falo na relação mãe e bebê 
(JORGE; FERREIRA, 2011), visto que a mãe há muito alimenta, inconscientemente, o desejo de ter seu falo, seu filho, processo resultante de seu complexo de Édipo. Nesta condição, o pai, o nome-do-Pai, entraria com a função castradora em tal processo, sendo castrados mãe e filho, incidindo sobre o vínculo fálico entre mãe-filho. Com a castração, a mãe é lembrada que o filho não pode voltar ao seu ventre, ser um objeto fálico, usual como foi um dia, e é lembrado ao filho que ele não pode ser o falo da mãe. $A$ palavra do pai, sua função castradora, castra a mãe de ter $o$ falo e a criança de ser o falo (NASIO, 1997).

É através das diferenças anatômicas do homem e da mulher e da resolução do seu complexo de Édipo, que o homem encontra-se no lugar de ser o falo, enquanto a mulher, no lugar de ter o falo. Dor (1997, p. 25) explica que "não devemos nos esquecer, simplesmente, de que somos sempre, como sujeitos, efeitos do significante", extenuando mais, efeitos daquilo resultante da significação do falo em nossas vidas, seres desejosos e que desejam (gerando um circuito, o circuito do desejo). Ele fala que Lacan introduz, na tríade edipiana mãe-pai-criança, o elemento falo, destacando-o como central nessa relação, pois é através dele que os desejos dos envolvidos serão decorridos.

Assim, já é possível pontuar a tríade edipiana na correlação falo-consumo, pois na tríade da relação de compra: consumidor-mercadoria-desejo, o falo não deixa de estar presente. $O$ falo empreende como significante com a delegação de tamponar essa falta que constitui as pessoas enquanto sujeitos do desamparo (comum a todos), fazendo, desse modo, a mercadoria e/ou o consumir a mercadoria, a maneira de se "aplacar" a angústia de se ter que assumir a posição de sujeitos faltosos, já que ninguém tem o falo, desprendendo-se do narcisismo mais primário, aquele referente ao já discutido estado de permutação com a mãe, em que se é o centro de sua vida, o seu falo. O que se tem para dizer é que a condição de faltosos é irremediável.

\section{A sociedade que consome}

Sociedade de consumo, começa Barbosa (2010), é algo de difícil definição, pois, segundo a autora, cada sociedade, no mundo pós-moderno, com sua cultura específica, diferente ou não da brasileira, consome diversos produtos e isso não significa, necessariamente, que estas poderiam ser classificadas com o rótulo de sociedade de consumo. Então interpela que a análise do termo geralmente vem acompanhada de conceitos como cultura do consumo, consumismo, cultura de consumidores e outros mais e defende que, quase sempre, colocam-se os conceitos como sinônimos, mas que precisam ser entendidos de um modo singular de cada um, porém, não tornando a relação sinônima com o primeiro conceito, errôneo. Sociedade do consumo seria àquela que consome mercadorias de modo desenfreado e que não parece, nunca, se satisfazer. O consumo está intimamente ligado à cultura da sociedade que se tem como objeto de estudo, do contexto em que se estuda, dos aspectos sociológicos presentes, inclusive o aspecto econômico.

Baudrillard (2010, p. 13) descreve um ponto que nos parece ser muito interessante:

À nossa volta, existe hoje, uma espécie de evidência fantástica do consumo e da abundância, criada pela multiplicação de objectos, dos serviços, dos bens materiais, originando como que uma categoria de mutação fundamental na ecologia da espécie humana. Para falar com propriedade, os homens da opulência não se encontram rodeados, como sempre acontecera, por outros homens, mas mais por objectos.

A ligação desta citação com a passagem de Barbosa (2010, p. 32) é inegável, pois ela diz que o consumo se tornou o foco central da vida social e cita que práticas sociais, valores culturais, ideias, aspirações e identidades são dirigidas pelo consumo, ao invés de serem direcionadas para "outras dimensões sociais, como trabalho, cidadania, religião, entre outros".

Existem muitas discussões pertinentes que podem advir do debate da sociedade de consumo, porém, o foco da discussão está na relação falo e mercadoria, isto é, no comportamento fálico diante do consumo, pois como complementa Barbosa (2010, p. 11), "a sociedade parece emergir de um conjunto de suposições sobre a cultura contemporânea que são tomadas como dados e quase nunca desafiadas criticamente". Ora, sempre se leva a discussão para o âmbito capitalista, econômico ou mesmo sociológico, ainda assim, com base na observação e estudos estatísticos, não valorizando os outros fatores inerentes a essa sociedade que consome e pouco importando em desafiar a vasta compreensão de algo tão complexo. Vê-se a historicidade do consumo, ser permeada desde séculos atrás, fosse no escambo durante a idade antiga ou no século XVIII, com a revolução industrial, responsável por mudar drasticamente o caráter do consumo, criando uma configuração em que a sociedade se perfaz até hoje, na pós-modernidade, o mito da igualdade, de que todos podem e devem ser felizes (BAUDRILLARD, 2010).

A relação a se fazer entre falo e mercadoria é pertinente e aqui encontra-se a hipótese: ao se falar da dissolução do complexo de Édipo, entende-se que todas as pessoas estão no 
lugar de sujeitos faltosos, faltosos quanto ao falo, pois ele falta, afinal ninguém o é ou o tem, então temos o resultante do significante falo, a significação do objeto fálico antes, durante e depois do nome-do-pai (JORGE; FERREIRA, 2011). 0 desejo, assim, vinculado à mãe e/ou pai, descamba para o consumo, consumo de mercadorias, e empregam-se mercadorias como tudo aquilo que se pode adquirir através da compra, troca e/ou ganho, como produtos objetais, serviços, utensílios, entre outros.

Daí a crença de que se vive numa sociedade de consumo insaciável (BARBOSA, 2010), pois se cria um circuito do desejo, considerando que se deseja porque há falta, porque os sujeitos são faltosos, fato que parece obrigá-los a consumir sempre, como cita Mezan (2011), que em nossa sociedade, dita por ele, narcisista, coage-se a utilização de objetos cada vez mais inúteis, como a percepção da obrigatoriedade de trocar um celular ou adaptar-se a moda vigente. Todavia, temse de tomar cuidado ao fazer uma crítica moralizante a essa sociedade e como dito anteriormente, está se propondo uma análise crítica, mas não moral, dos atos de compra. Barbosa (2010) enfatiza que se vive rente a cultura do consumidor e que produtos, experiências e serviços foram feitos para alimentarem o mercado.

Birman diz (2011, p. 89) que "é preciso reconhecer que, na passagem da modernidade para a dita pós-modernidade, algo da ordem do sujeito e do desejo se transformou radicalmente", - inconsciente - assim, diz-se que consome-se devido aos movimentos inconscientes mais do que se pode crer e o falo tem mais ligação com isso do que imagina, não excluindo, obviamente, os aspectos intricados a isso, a questão social e, inclusive, o sistema econômico vigente no contexto, afinal o psiquismo não caminha solitariamente.

Acredita-se ser possível correlacionar a postura fálica do homem com a cultura do consumo, visto que, utilizam-se as mercadorias como fontes de prazer, um prazer, um gozo que pode ser uma fonte inesgotável, mas vazia (realmente), fonte de prazer, que adoece, ludibria o ser humano, numa constante repetição de substituição de prazer por outro, buscando-se melhor realizar-se socialmente, isso porque é assim que estão as relações sociais, é assim que a sociedade vem se estruturando há anos, e intensificando-se no século XXI. Não é possível inferir que isso seja um aspecto pós-moderno, pois não é, todavia, é muito mais fortalecido hoje em dia, em um período onde o desamparo se faz muito mais presente, onde a família parece estar mais ausente, onde as relações amorosas parecem mais fugazes, as amizades mais distantes e ligadas por redes de acesso à internet, os desejos pessoais mais intricados ao consumo de mercadorias, em que o acúmulo de bens se torna um objetivo de vida e felicidade eterna, vendidos pela economia capitalista que preza, justamente, o capital.
É curioso como Baudrillard (2010), sociólogo, parece ter tido uma conversa face a face com Lacan, pois ele descreve que nessa sociedade de consumo, se consome tanto e por tão poucas razões, que a mercadoria, o discurso do consumo, metaforicamente, empreende por seu próprio excesso, a imagem de um dom, isto é, do espetaculoso, do prodigioso, ou seja, pode-se refletir e pensar no poderoso, aquele que supostamente é poderoso, supostamente tem o poder, supostamente tem 0 falo, assim como o pai que supostamente é detentor do falo e que o torna o desejo da mãe ou da mãe que tem alguma coisa que a torna desejo do pai - o dom, o dom de ser desejo do Outro (COSTA, 2011), de alguém.

Comumente, se vive em uma sociedade, cujas pessoas, buscam felicidade através do consumo, enquanto o mercado aproveita o consumo para vender felicidade. A retórica parece uma colossal falácia, porém que se sustenta como verdade de um jeito ou de outro. Duarte (2011), em sua releitura analítica da obra A dialética do esclarecimento, de Adorno e Horkheimer, apregoa que o ser humano demanda seu poder sobre a natureza buscando sentido para sua vida, quem sabe, tentando preencher algum vazio. Pensando, psicanaliticamente, esse vazio, baseado no todo já discutido até este ponto, esse vazio poderia muito bem ser a ausência do falo, em sua suposta existência.

Com essa ideia na cabeça, consome-se para validar algo em que se acredita, inconscientemente, poder possuir, de alguma forma, em objetos táteis ou serviços baratos demais se comparados às exigências de nossos desejos mais tenros, um preenchimento, um sentido, uma significação para uma vida. Freud (2010b, p. 29) fala, excepcionalmente, que a finalidade e intenção da vida dos homens são de fácil apontamento: "eles buscam a felicidade, querem se tornar e permanecer felizes". Ele ainda prossegue, explicando que isso remete a dois lados, inclusive, elaborados na introdução, que o homem deseja a total ausência de qualquer desprazer ou dor, enquanto possam viver intensos prazeres. Freud diz que é neste último ponto, "viver intensos prazeres" que está a real "felicidade".

Pensando assim, a pieguice do ditado "dinheiro não compra felicidade" mostra-se inverídica. Realizar seus desejos materiais traz, certamente, algum gozo ao consumidor, por isso este consome de novo, de novo e de novo. Claro, se algo é de desprazer, doloroso, então abstém-se disso e intensificase as fontes de prazer. Quando se pensa no narcisismo, exemplificam-se com produtos de beleza e a vaidade, em que algumas pessoas, na tentativa de parecerem mais joviais do que cronologicamente são, os utilizam de forma demasiada. Neste sentido, já há um exemplo claro da busca da felicidade e da prevenção do desprazer: consumir para manter-se jovial = felicidade; parecer menos jovem = desprazer. 
Baudrillard (2010, p. 49) delineia a discussão tão caricatamente, chegando a dizer, que de um ponto de visa antropológico, porém ingênuo, há uma propensão natural para a felicidade. Ele, ainda, complementa: "[..] A felicidade constitui a referência absoluta da sociedade de consumo, revelando-se como equivalente autêntico da salvação", ou seja, trazendo para a discussão psicanalítica, pode-se relacionar essa salvação à salvação da angústia presente ao que falta a qualquer sujeito, o falo, uma forma de apregoar que o suposto não é tão suposto. Freud (2010b) escreve que a felicidade é efêmera, breve, pois a satisfação de nossas necessidades represadas é efêmera. Reporta-se o nexo entre consumo e esses curtos momentos de felicidade. $\mathrm{O}$ consumo funcionaria como uma fonte recarregável de baterias, isto é, consome-se para que se "recarregue de felicidade", como se recarregasse o combustível do carro ou bateria do celular permanecendo-se em constante sentimento de prazer, aceitando-se o "tanque vazio ou bateria descarregada".

\section{CONSIDERAÇÕES FINAIS}

Estamos, todos, no lugar de sujeitos faltosos. O falo é um significante, um elemento meramente subjetivo, mas com uma importância na constituição psíquica que ultrapassa a menção do mero. Na angústia decorrida do complexo de Édipo e da castração, volta-se para o sentindo do desprazer, algum modo de lograr os sentimentos de completude e poder, outrora castrados. Uma das saídas que se dá, rente ao contexto social vigente, é o consumo. Aliar essas questões, o falo e a sociedade do consumo foi exequível e os resultados descobertos demonstraram-se curiosos e intrigantes, tendose a hipótese de que se tenta tamponar a falta do falo com mercadorias, como se isso fizesse a posição de sujeito faltosos deixar de existir, sido comprovada.

Precisa-se fazer uma leve recapitulação sobre o que se discutiu: o falo surge na relação mãe, criança, pai, personificando-se acentuadamente na fase fálica, daí a denominação da fase derivar do termo falo. Sabe-se que com a dissolução do complexo de Édipo, a psique se encontrará diante do correlato ser e ter o falo e que far-se-á a passagem do ser para o ter, afinal, ser, ninguém é o falo, assim como ninguém o tem (DOR, 2003). Ninguém pode ter o falo, sendo este um elemento significante, representativo de um desejo, algo completamente subjetivo, todavia, que se tenta personificar em formas objetais, como as mercadorias.

Deste modo, frente à perspectiva do próprio conceito do liberalismo capitalista, a busca do lucro, o mercado utiliza esse circuito de desejo inconsciente para criar consumidores que consomem, muitas vezes, sem necessidade, sem mesmo terem reais condições de pagar por aquilo. O desejo inconsciente fala mais alto e toma partido na busca do prazer efêmero sem mesmo pesar qualquer possibilidade de desprazer futuro naquilo, como acúmulo de dívidas, de objetos que nem se usa, compras por impulso, por compulsão, etc. Socialmente, a consciência desses movimentos de consumo pode ajudar a gerir muito melhor um modo mais saudável da comunidade viver dentro do paralelo do capitalismo e do consumo, mediante o pensamento crítico desenvolvido e do não mais consumir por consumir.

Tamponar a falta do falo com objetos ou serviços porque nosso narcisismo não consegue lidar com a realidade de supostos detentores do falo, vai além de um circuito do desejo ou qualquer ditadura do gozo, demonstra ainda o modo como passamos pelo complexo de édipo e ascende a discussão de como deve ser ou seria um processo legitimamente saudável da dissolução dessa fase. Assim, a sociedade do consumo cresce e se desenvolve mais e mais em um suposto alívio da angústia do lugar de faltosos. Sublimar essa angústia deve ser a saída para muitos de nós, pois somente assim, talvez, não nos tornemos reféns do nosso próprio "circuito do consumo".

\section{REFERÊNCIAS}

BARBOSA, L. Sociedade de Consumo. Rio de Janeiro: Zahar, 3. ed., 2010.

BAUDRILLARD, J. A sociedade de consumo. Lisboa: Edições 70 Arte \& Comunicação, 2010.

BIRMAN, J. Mal-estar na atualidade: a psicanálise e as novas formas de subjetivação. Rio de Janeiro: Civilização Brasileira, 8. ed., 2011.

COSTA, T. Édipo. Rio de Janeiro: Zahar, 1. reimp., 2011.

DOR, J. Estruturas e clínica psicanalítica. Rio de Janeiro: Taurus editora, 4. ed., 1997.

Introdução à leitura de Lacan: o inconsciente estruturado como linguagem. Porto Alegre: Artmed, 2 2 a reimp., 2003, p.71- 76.

DUARTE, R. Adorno/Horkheimer \& a dialética do esclarecimento. Rio de Janeiro: Zahar, 3. reimp., 2011.

FERREIRA, A. B. de H. Mini Aurélio. Curitiba: Posigraf, 6. ed. rev. e ampl., 2004, p. 317.

FREUD, S. Introdução ao narcisismo, ensaios de metapsicologia e outros textos (1914-1916). São Paulo: Companhia das Letras, 2010a, p. 13 - 50.

O eu e o id, "autobiografia" e outros textos (19231925). São Paulo: Companhia das Letras, 2011, p. 169 175, p. $203-213$, p. $283-299$.

- O mal-estar na civilização, novas conferências introdutórias à psicanálise e outros textos (1930-1936). São Paulo: Companhia das Letras, 2010b. 
GIL, A. C. Métodos e técnicas de pesquisa social. São Paulo: Atlas, 6. ed, 2008, pag. 50.

KAUFMANN, P. Dicionário enciclopédico de Psicanálise: o legado de Freud e Lacan. Rio de Janeiro: Zahar, 1996, p. $191-195$.

KOOGAN/HOUAISS. Enciclopédia e dicionário ilustrado. Rio de Janeiro: Seifer, 3. ed., 1998, p. 659.

JORGE, M. A. C.; FERREIRA, N. P. Lacan: o grande freudiano. Rio de Janeiro: Zahar, 4. ed., 2011.

LACAN, J. Escritos. Rio de Janeiro: Jorge Zahar Editor, 1998, p. 692-703.

LAPLANCHE, J.; PONTALIS, J. B. Vocabulário de Psicanálise. São Paulo: Martins fontes, 2008, p. $166-168$.

MARTINS, G. de A.; LINTZ, A. Guia para elaboração de monografias e trabalhos de conclusão de curso. São Paulo: Atlas, 2. ed, 2011, p. 15.

MEZAN, R. Intervenções. São Paulo: Casa do Psicólogo, 2011, p. $211-229$.

NASIO, J. D. Lições sobre os 7 conceitos cruciais da Psicanálise. Rio de Janeiro: Jorge Zahar, 1997, p. $33-41$.

ROUDINESCO, E.; PLON, M. Dicionário de Psicanálise. Rio de Janeiro: Jorge Zahar editor, 1998, p.708- 711.

SAFATLE, V. Lacan. São Paulo: Publifolha, 2007.

XIMENES, S. Minidicionário Ediouro. Rio de Janeiro: Ediouro, 7. ed., 1999, p. 288.

Submissão: 02/09/2019

Aprovado para publicação: 29/09/2019 